\title{
Experimental Study on Alternating Current Corrosion of Pipeline Steel in Alkaline Environment
}

\author{
Yan Yang, Shuli Wang, Chuang Wen*
}

School of Petroleum Engineering, Changzhou University, Zhonglou District, Changzhou, Jiangsu, 213016, China

*E-mail: chuang.wen@cczu.edu.cn

doi: $10.20964 / 2016.08 .64$

Received: 18 May 2016 / Accepted: 16 June 2016 / Published: 7 July 2016

The variation of the topsoil $\mathrm{pH}$ value in the X70 steel surface was studied under the $\mathrm{AC}$ corrosion process. The cyclic voltammetry technique was employed to investigate the AC action mechanism on the X70 pipeline steel in a soil environment. The results show that the alternating current has a great effect on the surface soil $\mathrm{pH}$ value. The corrosion mechanism of a metal suffered AC interference in an alkaline environment is that the AC changes the polarization potential and reduces the $\mathrm{pH}$ value of the surface soil. The coupling potential of the mixed alternating and direct currents presents a periodic oscillation in the electrode surface, which destroys the passivation of the X70 steel. The electrode surface is covered with a large amount of $\mathrm{Fe}(\mathrm{OH})$ ads, when the potential is in the range of the active dissolution potential of the X70 steel. In this condition, the hydroxides and oxides will form preferentially. In a different charge transfer process, the hydroxide, as the inhibitor of the passivation film, has an important impact on the metal corrosion. The increase of the corrosion rates is under the control of the transfer process.

Keywords: AC corrosion; alkaline environment; X70 steel; corrosion mechanism

\section{$\underline{\text { FULLTEXT }}$}

(C) 2016 The Authors. Published by ESG (www.electrochemsci.org). This article is an open access article distributed under the terms and conditions of the Creative Commons Attribution license (http://creativecommons.org/licenses/by/4.0/). 